\title{
Kanserli erkek hastalarda cinsel sorunlar
}

\section{Sexual problems among male patients with Cancer}

\author{
Ayșe Çil Akıncı®o, Cemile Savcı®o
}

\section{öz}

Kanserli bireylerin cinsel fonksiyonu fiziksel, duygusal, sosyal, spiritüel ve kültürel birçok faktör arasındaki karmaşı etkileşim sonucu etkilenmektedir. Cinsel fonksiyondaki değişiklikler çeşitli nedenlerle hastalar tarafından sağlık profesyonellerine iletilmemekte ve sağlık profesyonelleri tarafından da değerlendirilmemektedir. Hastalara kanser ve tedavisi nedeniyle oluşabilecek cinsel fonksiyon değişiklikleri hakkında bilgi verilmesi ve oluşan cinsel sorunların çözümüne yönelik destek sağlanması hastaların bu süreci daha konforlu geçirmelerini sağlayacaktır. Tanı, tedavi ve bakım sürecinde hastalarla iletişim halinde olan sağlık profesyonelleri cinsel sorunların belirlenmesi ve yönetiminde etkin rol alabilirler. $\mathrm{Bu}$ derlemede kanserli erkek hastalarda kanser ve tedavisi nedeniyle ortaya çıkan cinsel sorunlar ele alınmıştır. Kanserli erkek hastalarla çalışan sağlık profesyonellerine cinsel sorunların nedenleri ile ilgili bütüncü bir bakış açısı sağlaması hedeflenmiştir.

Anahtar Kelimeler: Cinsel sorunlar, erkek, kanser, tedavi

\section{ABSTRACT}

The sexual function of individuals with cancer is affected by the complex interaction between physical, emotional, social, spiritual and cultural factors. Changes in sexual function are not reported to health professionals by patients due to various reasons and are not evaluated by the health professionals. Providing information about the changes in sexual function that may occur due to cancer and its treatment and providing support for the solution of the sexual problems that may occur will enable the patients to experience this process more comfortably. Health professionals who are in contact with patients in the diagnosis, treatment and care process can play an active role in the identification and management of sexual problems. In this review, sexual problems caused by cancer and its treatment among male patients with cancers are discussed. The review aims to provide a holistic perspective to health professionals working with male patients with cancer about the causes of sexual problems.

Keywords: Sexual problems, male, cancer, treatment
C insellik özel bir konu olmasının yanında yaşamın önemli bir parçasıdır. ${ }^{[1,2]}$ Cinsel fonksiyon bozukluğu bireylerde fiziksel, ruhsal ve sosyal sorunlara neden olabilmektedir. Sağlıklı bireylerde olduğu gibi kanserli bireylerde de cinselliğin sürdürülmesi önemli bir işlev iken ${ }^{[3]}$ kanser tanısı ve tedavisi nedeniyle oluşan fiziksel, duygusal, sosyal ve manevi etkiler hastaların cinsel fonksiyonunu etkileyebilmektedir. Hem hasta hem de partnerinin "hasta kişi seksi değildir” şeklindeki kültürel görüşleri de cinsel fonksiyonlar üzerinde etkili olabilmektedir. ${ }^{[4-6]}$

\section{KANSERIN CINSEL FONKSIYONLAR ÜZERINE ETKISI}

Kanser tanısı ve tedavisi istek, ereksiyon, orgazm ve doyum da dâhil olmak üzere cinselliğin tüm aşamalarını

İstanbul Medeniyet Üniversitesi, Sağlık Bilimleri Fakültesi, Hemşirelik Bölümü, İstanbul, Türkiye

Yazışma Adresi/ Correspondence:

Dr. Öğr. Üyesi Cemile Savcı

Atalar Mah., Sehit Hakan Kurban Cad., 34862 Kartal / Cevizli / İstanbul, Türkiye

Tel: $\quad$ +902162804101

E-mail: cemilesavci@gmail.com

Gelis/ Received: $\quad 17.06 .2019$

Kabul/ Accepted: $\quad$ 29.08.2019 etkileyebilmektedir. ${ }^{[7]}$ Kanser ve tedavisi nedeniyle oluşan yorgunluk, ağrı, bulantı, kusma, dispne, duyu kaybı ve hareket kısıtlllığı gibi fiziksel şikayetler ${ }^{[6,8-10]}$ yanında saç dökülmesi, kilo kaybı, kilo alma, vücutta oluşan skarlar, organ kayıpları, yara drenajı gibi fiziksel görünümdeki ve beden imajı algısında değişiklikler ${ }^{[5,6,9,11-13]}$ de cinsel fonksiyonu etkileyebilmektedir. Tanı ve tedavi sürecinde hastalar ve partnerleri tarafindan deneyimlenen anksiyete ve depresyon gibi psikolojik durumdaki dalgalanmalar ${ }^{[6,12,13]}$ ile birlikte bu dalgalanmaları kontrol altına almak için kullanılan ilaçların yan etkileri ${ }^{[4]}$ cinsel fonksiyonu etkileyebilmektedir. Cinsel organları etkileyen kanserler ve tedavileri nedeniyle organları inerve eden sinirlerin hasar görmesi ve kan desteğinin azalmasına ilave olarak ${ }^{[5,10,13]}$, kanser tedavisinde kullanılan hormonların kilo alma, sıcak basması, duygusal değişiklikler gibi yan etkileri de cinsel fonksiyonu etkilemektedir. İlave sağlık sorunlarına ait semptomlar ya da bu semptomları kontrol altına almak için kullanılan ilaçların yan etkileri ${ }^{[8]}$ de cinsel fonksiyonu etkilemektedir. Hasta ve ailesinin dini inançları, kültürel değerleri ve sosyal normları $1^{[6,8,12,13]}$, ilişkideki uyum durumu, iletişim eksikli$\breve{g}^{[6,12,13]}$ gibi sosyal faktörler de cinsel sorunların oluşmasında etkili olabilmektedir. Tüm bunlara ilave olarak kanser sürecinde ortaya çıkabilecek geçici veya kalıcı infertilite ${ }^{[11]}$ sorunları da cinsel fonksiyonu etkileyebilmektedir. 
Hastalar tedavi sürecinde yaşadıkları cinsel sorunları, tedavinin beklenen bir sonucu olduğu ve kanser sonrası cinsel fonksiyon bozukluğuna yönelik etkili bir tedavi olmadığı şeklindeki düşünceleri nedeniyle sağllk profesyonellerine iletmemektedirler ${ }^{[6]}$ Sağlık ekibinin hastalara kanser sürecinde ortaya çıkabilecek olası cinsel sorunlar ve tedavi seçenekleri hakkında destek vermesi hastaların bu süreci daha rahat geçirmesine katkı sağlayacaktır. ${ }^{[11]}$ Cinselliğin hareket, yeme-içme, solunum gibi yaşamsal öneme sahip bir aktivite olarak görülüp rutin olarak değerlendirilmesi gerekmektedir. Kanser öncesi dönemdeki cinsel sorunlar, tedaviye bağlı gelişebilecek cinsel sorunları daha da kötüleştirebileceğinden tedavi öncesi cinsel fonksiyon değerlendirmesinin yapılması gerekmektedir. ${ }^{[14]}$ İlk tanılamada "tanıdan bu yana cinselliğinizde hangi değişimleri hissettiniz" şeklinde sorular sorulması, hastalar ve sağlık profesyonellerinin cinsel sorunlar konusunda konuşmalarını kolaylaştırır. ${ }^{[15]}$

\section{KANSER BÖLGESINE GÖRE CINSEL SORUNLAR}

Prostat, testis, penis ve mesane gibi ürogenital sisteme ait organların kanserlerine ilave olarak kolorektal ve anal kanserler, baş boyun kanserleri ve hematopoetik kanserlerde de cinsel sorunlar oluşabilmektedir.

\section{Prostat Kanseri}

Kanser ve tedavisinin cinsel organlar üzerine doğrudan etkisi nedeniyle prostat kanseri olan hastalar cinsel problemlerle karşı karşıya kalırlar. ${ }^{[16]}$ Prostat kanseri tanısı koymak amacıyla yapılan tanı işlemleri yanında prostat kanseri tanısı konulmuş olması nedeniyle yaşanan psikolojik süreçler ve uygulanan tedaviler cinsel fonksiyonu farklı düzeylerde etkileyebilmektedir. Tanı amaçlı yapılan biyopsi sonrası libido kaybı ve impotans riski artmaktadır. ${ }^{[17]}$ Yaşam beklentisi 10 yıldan az, klinik açıdan sınırlı, erken evre ve düşük hacimli yaşlı prostat kanserli hastaların müdahalesiz izlem sürecinde de cinsel fonksiyon bozukluğu riski vardır. ${ }^{[7,18]}$ Radikal prostatektomi ve radyoterapi ile karşılaştırıldığında müdahalesiz izlem sürecinin cinsel fonksiyon üzerindeki etkisi oldukça azdır. ${ }^{[19]}$ Lokal olarak ilerlemiş prostat kanseri kriyoterapi ile tedavi edilebilirken biraz daha ileri evredeki hastalarda prostatektomi ya da bilateral orşiektomi yapılmaktadır. ${ }^{[8]}$ Prostat kanserinde yaygin olarak kullanılan radikal prostatektomi libido kaybına neden olabilmekte ${ }^{[8,17,20]}$ işlem sırasında seminal kanalların çıkarılması ve vas deferensin kesilmesi kuru orgazma, azalmış orgazmik tatmine ve orgazm sırasında üriner inkontinasa neden olmasından dolayı cinsel aktiviteden kaçınmaya yol açmaktadır. ${ }^{[16]}$ Yine cerrahi işlem sırasinda erektil fonksiyonlarda görev alan kavernöz sinirlerin etkilenmesi nedeniyle penis boyunda ve çapında küçülmeye neden olabilmektedir. ${ }^{[16]}$ Erektil fonksiyonların düzelmesi yönünden tek taraflı sinir koruyucu cerrahiye göre bilateral sinir koruyucu cerrahi daha etkindir. ${ }^{[21]}$ Buna rağmen sinir koruyucu cerrahi sonrası sinirlerin iyileşmesi ve erektil fonksiyonların düzelmesi 18-24 ay sürebilmektedir. ${ }^{[16]}$ Bilateral orşiektomi libidonun kademeli olarak azalmasına, erektil fonksiyon bozukluğuna, jinekomastiye, penil atrofiye ve vücut görüntüsünün değişmesine yol açarak cinsel işlev bozukluğuna neden olmaktadır. ${ }^{[8]}$

Prostat kanseri tedavisinde kullanılan radyoterapi bağırsak ve üriner fonksiyon bozuklukları yanında erektil fonksiyon bozukluğuna yol açabilmektedir. ${ }^{[20-22]}$ Radyoterapi (RT) tedavisi gören hastalar cerrahi işlem uygulanan hastalar kadar olmasa da cinsel fonksiyonlarında azalma yaşamaktadırlar. Cerrahi işlem gören hastalarda cinsel fonksiyonlar zaman içerisinde iyileşme eğiliminde olmasına rağmen, RT hastalarının cinsel fonskiyonlarının tedaviden hemen sonra en yüksek seviyede olduğu ve daha sonra kademeli olarak azalmaya başladığı belirtilmemektedir. Cinsel fonksiyonlardaki kademeli azalmanın RT sonrası oluşan fibrozisin zaman içerisinde ilerlemesinden kaynaklandığı düşünülmektedir. Brakiterapi ve çekirdek implantlar da cinsel sorunlara neden olmasına rağmen etkileri cerrahiden daha azdır. ${ }^{[16]}$ Yine erken dönem prostat kanserinde brakiterapi tedavisinden hemen sonra oluşan yorgunluk uzun süre devam eden şiddetli impotans riski oluşturabilmektedir. ${ }^{[17]}$ Relaps veya hormon duyarlı metastatik prostat kanserli hastalarda uygulanan androjen yoksunluğu tedavisinde serum testosteron seviyelerinin azalması sıcak basmasına, yorgunluğa, emosyonel dalgalanmaya, uyku kalitesinde azalmaya, jinekomastiye, libidoda azalmaya, erektil fonksiyon bozukluğuna ve cinsel ilişki sıklığında azalmaya neden olabilmektedir. ${ }^{[6,16,18,20,23]}$ Ayrıca, başarısızlık korkusu ve psikolojik sorunlar da prostat kanserli hastalarda cinsel fonksiyon bozukluğuna neden olabilmektedir. ${ }^{[8]}$

\section{Testis Kanseri}

Testis kanseri genç erişkinlerde sık görüldüğünden hastalar cinsel kaygılar yaşayabilmektedir. ${ }^{[23]}$ Testis kanseri tedavisinde kitlenin büyüklüğüne ve yayılımına göre orşiektomi, retroperitoneal lenf nodu diseksiyonu, pelvik kitlenin çıkartılması şeklinde cerrahi girişimler uygulanmakta; cerrahi girişim sonrası kemoterapi veya radyoterapiyle tedaviye devam edilmektedir. Tek taraflı orşiektomi genellikle infertilite veya cinsel fonksiyon bozukluğuna neden olmazken, bilateral orşiektomi testosteron kaybına bağlı sterilite ve libido azalmasına neden olabilmektedir. ${ }^{[8,24]}$ Her ne kadar tek taraflı orşiektominin cinsel fonksiyon bozukluğuna neden olmadığı bildirilse de, bir çalışmada bu hastaların \%34,5'inde 
cinsel istekte azalma, \%41,6'sında cinsel aktivitede azalma, \%31,5'inde erektil disfonksiyon, \%24,4’ünde ilişki sırasında ereksiyonu sürdürme yeteneğinde bozulma ve \%95,4’ünde genel cinsel doyumda azalma olduğu bildirilmektedir. ${ }^{[25]}$ 36 araştırmanın meta-analizinde, testis kanserli hastalarda en sık ejakülasyon sorunlarının yaşandığı ve bu sorunun retroperitoneal alandaki cerrahi girişimle ilgili olduğu bildirilmiştir. ${ }^{[26]}$ Ejakülasyonu ve fertiliteyi korumak için retroperitoneal lenf nodu diseksiyonu sırasında mümkün oldugunca sinir koruyucu cerrahi girişimler tercih edilmektedir. [12] Testis kanserinde erektil fonksiyon bozukluğunun daha az görüldüğü ve radyoterapiye bağlı geliştiği bildirilmektedir. Ereksiyon ve ejakülasyon sorunları dışında kalan diğer cinsel fonksiyon bozukluklarının tedavi yöntemiyle ilişkili olmadığı, testis kanseri gibi hayatı tehdit edici genito-üriner bir hastalıkla yüzleşmeden kaynaklı psikolojik sorunlar nedeniyle ortaya çıkabileceği bildirilmektedir. ${ }^{[26]}$

\section{Penil Kanserler}

Penis ve erkek üretra kanseri nadirdir. ${ }^{\left[{ }^{[]}\right.}$Bu kanserde uygulanan tedavi kısmi veya total penis amputasyonu, radyoterapi veya lazer tedavisidir. Lezyon erken evrede ve yayılmamışsa uygulanan tedaviler sonucu cinsel fonksiyon ve memnuniyet belirli bir dereceye kadar etkilenebilir. Lazer tedavisi sonrasında hastaların çoğu cinsel yaşamdan doyum alabilmesine rağmen, daha invaziv girişimlerde bu olasıllk azalmaktadır. Alınan doku miktarı yanında penis kanseri geçirme nedeniyle oluşan damgalanma gibi psikososyal sorunlar cinsel fonksiyonu etkileyebilmektedir. Parsiyel penektomide, penis uzunluğundaki azalmaya rağmen erektil, ejekülatif veya orgazmik yetenek kaybı olmaz. Total penektomili hastalarda ise kalan genital dokunun uyarılması orgazm oluşturabilirken erektil yetenek yoktur. ${ }^{[8,18]}$

\section{Mesane Kanseri}

Mesane kanserinde tanı ve tedavi amacıyla uygulanan tekrarlı sistoskopi erkeklerde ereksiyon ve ejekülasyon sırasında geçici ağrıya ve cinsel istekte geçici bir azalmaya neden olabilmektedir. ${ }^{[8]}$ Mesane kanserinde sıklıkla cerrahi tedavi uygulanmaktadır. Radikal sistektomi sonrası uzun dönemde prognoz iyi olmasına rağmen cinsel fonksiyonlarda azalma görülmektedir. ${ }^{[8,16,27]}$ Hastalarda cinsel fonksiyonun özellikle de erektil fonksiyonun korunması amacıyla sinir koruyucu cerrahi tercih edilebilmektedir. Mesane kanseri nedeniyle uygulanan sinir ve seminal kanalları koruyucu sistektomi standart sistoprostatektomi ile karşılaştırıldığında erektil fonksiyonların korunduğu ve cinsel yaşam kalitesinin tatmin edici olduğu bildirilmektedir. ${ }^{[28]}$ Üriner diversiyon, ürostomiler, yeni mesane ve üriner inkontinans nedeniyle ped veya diğer koruyucu malzemeleri kullanma mesane kanserli hastalarda beden imajı ve benlik sayg1sında azalmaya yol açarak cinselliği etkileyebilmektedir. İnkontinans sorunları hastanın duygusal ve sosyal izolasyonuna yol açabilmekte, tedaviye bağlı oluşan psikolojik etkiler nedeniyle hastalarda cinsel fonksiyon olumsuz etkilenebilmektedir. ${ }^{[8,16,27]}$

Mesane kanseri tedavisinde radikal RT, hastalarda dizüri ve üretral darlığa neden olabilmektedir. Üriner sorunlar dışında bağırsak fonksiyonları da etkilenebilmekte, diyare, dışkı aciliyeti ve dışkı inkontinansı oluşabilmektedir. Tüm bunlar cinsel fonksiyonu olumsuz yönde etkileyebilmektedir. RT uygulanan hastaların \%25'inde cinsel fonksiyonun orta ve şiddetli derecede etkilendiği, impotans ve cinsel istekte azalma sorunlarının ön planda olduğu bildirilmektedir. ${ }^{[29]}$

\section{Kolorektal ve Anal Kanserler}

Kolorektal kanserli hastalarda erektil ve ejekülatuvar fonksiyon bozuluğu görülmektedir. ${ }^{[16]}$ Preoperatif dönemde kolorektal kanserli hastalarda cinsel problem yaşanmazken cerrahi girişim sonrası cinsel fonksiyon bozukluğu yaşayan erkeklerin oranının \%5 ile \%88 arasında değiştiği bildirilmektedir. ${ }^{[30]}$ Kolorektal kanser cerrahisi sonrası sinir hasarı oluşması ve etkilenen bölgenin genital organlara yakın olması ürogenital fonksiyon bozukluklarına neden olmaktadır. ${ }^{[16]}$ Daha aşağı bölgedeki tümörlerin daha fazla cinsel fonksiyon bozukluğu ile ilişkili olduğu bildirilmektedir. [30,31] Rektum kanserlerinde, uygulanan tedavinin sinir liflerinde hasar oluşturabilmesi nedeniyle cinsel fonksiyonun bozulma olasılığı yüksektir ${ }^{[2]}$ Preoperatif radyoterapi, stoma, cerrahi girişimler sırasında veya sonrasında oluşan komplikasyonlar, preoperatif cinsel aktivite durumu, ileri yaş cinsel fonksiyon bozukluğu ile ilişkili olabilmektedir. ${ }^{[31,32]}$ Rektal kanserlerde cerrahi girişim öncesi erkek hastaların \%91'i cinsel olarak aktif iken bu oranın cerrahi sonrası \%50’ye düştüğü bildirilmektedir. Cerrahi girişim sonrası libido kaybı (\%47), impotans (\%32), kısmi impotans (\%52), azalmış orgazm (\%41) ve boşalma sorunları (\%43) görüldüğü bildirilmektedir. ${ }^{[31]}$ Cerrahi girişim sonrası görülen cinsel fonksiyon bozukluğu sinir koruyucu cerrahi girişimler ile engellenebilmektedir. ${ }^{[33]}$ Son dönemlerde uygulanan laparoskopik uygulamalar da cinsel fonksiyonlar üzerinde koruyucu olabilmektedir. Açık rektal kanser rezeksiyonunun laparoskopik cerrahiye kıyasla daha yüksek oranda cinsel fonksiyon bozukluğu ile ilişkili olduğu bildirilmektedir. ${ }^{[28]}$ Laparoskopik rektum cerrahisi sırasında total mezorektal eksizyonu yapıldığında genel cinsel fonksiyon ve erektil fonksiyonun kötüleşebileceği de bildirilmektedir. ${ }^{[34]}$ 


\section{Baș ve Boyun Kanserleri}

Baş ve boyun kanserlerinde fonksiyon koruyucu cerrahi yöntemler kullanılmasına rağmen, cerrahi tedavi sonrası yüzde oluşan değişiklikler ve şekil bozuklukları, tükürük salgısında kalıcı değişiklikler, solunum ve konuşma değişiklikleri benlik saygısı ve beden imajında azalmaya neden olabilmekte ve cinselliği etkileyebilmektedir. İlave olarak alkol ve tütün yoksunluğu nedeniyle oluşan psikolojik stres, kanser tanısı konulmuş olması nedeniyle oluşan stigma da cinsel fonksiyon bozukluğuna neden olabilmektedir. ${ }^{[8,16]}$ Kemoterapi (KT) ve kemoRT tedavisine bağlı olarak ilk dönemlerde ilaçların yan etkileri nedeniyle cinsellik etkilense de zaman içerisinde cinsel fonksiyonun düzeldiği bildirilmektedir. Bir çalışmada, KT ve kemoRT tedavisine başlamadan önce baş ve boyun kanserli hastaların \%37'sinde cinselliğin azaldığı; 6 haftalık takipte bu oranın \%60'a yükseldiği, 12 aylık takipte \%37'a ve 24 aylık takipte \%24'e indiği bildirilmiştir. ${ }^{[35]}$

\section{Hematopoetik Kanserler}

Hematolojik kanserler ve tedavi yöntemlerinin cinsellik üzerindeki etkisi çok değişkendir. ${ }^{[36]}$ Hodgkin, non Hodgkin ve akut lösemili hastaların \% 23 ile 29 'unda cinsel yaşamın olumsuz etkilendiği bildirilmektedir. ${ }^{[37]}$ Hematolojik maligniteler nedeniyle KT veya kemoimmunoterapi tedavisi gören hastaların başlangıçtaki durumuna göre 1 ay sonrasında cinsel fonksiyonun azaldığ $1{ }^{[38]}$, altı ay sonra ise başlangıç düzeyine döndügü bildirilmektedir. ${ }^{[39]}$ Kemoterapötik ilaçlardan alkilleyici ajanlar primer hipogonadizme, cinsel istekte azalmaya, erektil fonksiyon bozukluğuna ve semen hacminde azalmaya vinkristin veya platin bazlı ilaçlar ise otonom sinir hasarı ile ereksiyon ve/veya ejekülasyonda azalmaya neden olabilmektedir. ${ }^{[2]}$ Tüm vücut RT'si nedeniyle oluşan vasküler hasar erektil fonksiyon bozukluğuna neden olabilmektedir. Tüm bu faktörlere ilave olarak, daha önce uygulanan kanser tedavilerinin pelvik sinirlere ve damar yapılarına zarar vermesi veya hormon üretimini azaltması, hematolojik transplantasyona yönelik yoğun hazırlık, kanser nedeniyle oluşan psikolojik stres, beden imajı değişikliği ve fiziksel görünüm ile ilgili endişeler cinsel sorunları daha da kötüleştirebilmektedir. ${ }^{[2,8,37]}$

\section{KANSER TEDAVILERININ CINSEL FONKSIYON ÜZERINE ETKISi}

Kanseri tedavi etmek için kullanılan KT, cerrahi tedavi, RT, kök hücre / kemik iliği transplantasyonu ve hormon tedavisi yöntemleri cinsel fonksiyon üzerinde doğrudan ve dolaylı etkiye sahiptir. ${ }^{[00,41]}$

\section{Kemoterapinin Cinsel Fonksiyon Üzerine Etkisi}

Kemoterapinin neden olduğu üreme sorunları ve cinsel fonksiyon bozukluğu ilacın türü, dozu, tedavi süresi, tedaviyi alan bireyin yaşı, cinsiyeti ve tedaviden sonra geçen süre ile ilişkilidir. KT sonrası oluşan bulantı-kusma, diyare, konstipasyon, stomatit, tad ve koku duyusundaki değişliklikler cinsel istek kaybına ve cinsel ilişki sıklığında azalmaya neden olabilmektedir. Kemoterapi yan etkilerini yönetmek için kullanılan antidepresanlar, antiemetikler, sedatifler, trankilizanlar, antihistaminikler, steroidler ve narkotikler ilaçlar erektil fonksiyon bozukluğu, cinsel istekte azalma ve cinsel tatminde azalmaya neden olabilmektedir. ${ }^{[8]}$ KT'ye bağlı gelişen alopesi ve kilo değişiklikleri cinsel açıdan bireyin çekicilik ve özgüven duygusunu azaltabilmektedir. Sinir hasarına neden olan bazı kemoterapötik ajanlar nadiren kalıcı nitelikte olabilen geçici erektil fonksiyon bozukluklarına neden olabilmektedir. Nörotoksik ajanlar prostatın ve sperm keseciklerinin kasılmasını sağlayan otonom sinirlerin harabiyetine neden olduğundan orgazm sırasında semen ejakülasyonu engellenebilmektedir. ${ }^{[42]}$ Tüm bunlara ek olarak sitotoksik KT'nin veriliş şekline, dozuna ve hastanın yaşına bağlı olarak gonadal hasar oluşabilmektedir. Gonadlarda hasar oluşturarak infertiliteye neden olan ilaçlar başta alkilleyici ajanlar olmak üzere, sitozin arabinosid, 5-florovasil, vinblastin, vinkristin, sisplatin ve prokarbazindir. Bu ilaçların kombinasyonları infertilitenin uzamasına neden olmaktadır. ${ }^{[8,43]}$ Sitotoksik KT alan hastaların çoğunda 8-12 haftada azospermi gelişmekte olup kemoterapinin dozu ve süresi kalıcı azospermi oluşmasında etkili olmaktadır. Bir diğer önemli nokta çok düşük dozlarda bile KT RT ile kombine uygulandığında spermatogenez çok ciddi oranlarda etkilenmektedir. ${ }^{[43]}$

\section{Cerrahi Tedavinin Cinsel Fonksiyon Üzerine Etkisi}

Cerrahi tedavi sonrası görülen postoperatif ağrı ve yorgunluk cinsel isteği birkaç hafta boyunca etkileyen en önemli iki semptomdur. Yine ekstremite amputasyonu, meme kayb1, radikal boyun disseksiyonu gibi cerrahi tedaviye bağlı beden imajında oluşan değişikler de cinsel isteği etkileyebilmektedir. Cerrahi işlemin yapıldığı alan, cerrahi sırasında çıkarılan organların fonksiyonlarındaki yetersizlikler, cerrahi işlem sırasında oluşan sinir ve doku hasarı gibi birçok faktör hastaların cinselliğini etkileyebilmektedir. Radikal prostatektomi ve sistektomiden sonra prostat ve seminal vesiküllerin alınmasına bağlı olarak kuru orgazm oluşabilmektedir. Prostat veya mesane kanserlerinin cerrahi tedavisi erektil sinir hasarı oluşturabilmekte ve bu durum ereksiyona sorunlarına neden olabilmektedir. Yine testis kanserinde tedavi amaciyla uygulanan retroperitoneal lenfadenoktemi sonrası retrograde ejakülasyon görülebilmektedir. ${ }^{[42]}$ 


\section{Radyoterapinin Cinsel Fonksiyon Üzerine Etkisi}

Radyoterapi nedeniyle oluşan yorgunluk, bulantı, kusma, diyare ve diğer semptomlar cinsel istek kaybına ve cinsel ilişki sıklığında azalmaya neden olabilmektedir. İnflamasyon, ağrı ve sınırlı hareket alanı cinsel aktiviteleri zorlaştırabilmektedir.

Prostat veya mesane kanserlerinin tedavisinde uygulanan primer pelvis RT'si erektil sinirin hasarına ve ereksiyon sorunlarına neden olabilmektedir. Cerrahi tedavide bu sorun operasyondan hemen sonra ortaya çıkarken, RT'de 18-36 ay gibi uzun bir süre sonra yavaş yavaş ortaya çıkabilmektedir. ${ }^{\left[{ }^{842}\right]}$ Yine RT sonrası oluşan testiküler aplazi infertilite oluşturabilmektedir. Geçici veya kalıcı azospermi yaş, doz, doku hacmi ve maruz kalma süresine bağlı olarak oluşabilmektedir. RT nedeniyle oluşan korku, depresyon, kaygı, stres, beden imajındaki değişiklikler ve benlik saygısında azalma gibi psikolojik etkiler de cinsel fonksiyonu değiştirebilmektedir. ${ }^{\left[{ }^{[]}\right.}$

\section{Kök Hücre / Kemik iliği Transplantasyonunun Cinsel Fonksiyon Üzerine Etkisi}

Yüksek doz KT ve total vücut RT’sinin birarada kullanılması nedeniyle oluşan yan etkiler cinsel fonksiyonu kötüleştirebilmektedir. Yine transplantasyon nedeniyle uzun süre hastanede yatma, mahremiyet eksikliği ve fiziksel temasın sınırlı olması da cinselliği etkileyebilmektedir. ${ }^{[2,8]}$ Kemik iliği transplantasyonu sonrası geç dönemde kronik yorgunluk, cinsel istekte azalma, beden imajında değişiklikler, gonadal disfonksiyon ve infertilite görülebilmektedir. Hastanın yaşı, tüm vücut RT’si, kombinasyon veya tek ajan KT kullanımı gonadal hasar ve infertilite oluşmasında etkilidir. Transplantasyon sonrası oluşan greft versus host hastalı̆̆ı peniste eğriliğe, ağrıya ve erektil fonksiyon bozukluğuna neden olabilmektedir. Arteriyojenik yetmezlik ile ilişkili erektil fonksiyon bozukluğu, ejakülasyon bozuklukları ve azalmış orgazm da sık görülen yan etkilerdendir. ${ }^{[2,8]}$ Her ne kadar cinsel aktivite ve doyumun iyileşmesi nakilden sonraki ilk 2 yılda meydana gelse de, kanser tedavisinden 5-10 yıl sonra bile cinsel fonksiyon bozukluğu yaşanabilmektedir. ${ }^{[2]}$

Sonuç olarak; kanser tanısı ve tedavisi cinsel fonksiyonu etkilemektedir. Ürogenital organ kanserleri yanında kolorektal ve anal kanserler, baş boyun kanserleri ve hematopoetik kanserlerde de cinsel sorunlar yaşanabilmektedir. Sağlık çalışanlarının hastalara kanser sürecinde ortaya çıkabilecek olası cinsel sorunlar ve çözümü hakkında danışmanlık vermesi hastaların bu süreci daha rahat geçirmesine olanak sağlayacaktır. Cinsel sorunların erken dönemde saptanabilmesi için cinsel sorunlara neden olan durumların sağlık çalışanları tarafından bilinmesi ve hastaların cinsel fonksiyonlarının rutin olarak değerlendirilmesi gerekmektedir.

Hakem Değerlendirmesi

Dış bağımsız

Çıkar Çatışması

Yazarlar çıkar ilişkisi olmadığını beyan etmişlerdir.

Finansal Destek

Herhangi bir mali destek alınmamıştır.

Peer-review

Externally peer-reviewed.

Conflict of Interest

No conflict of interest was declared by the authors.

Financial Disclosure

No financial disclosure was received.

\section{KAYNAKLAR}

1. Malik S, Brandenburg D. Practical Tips \& Advice for Overcoming Sexual Difficulties after Cancer \& Cancer Treatments (Chapter 6). In: Brandenburg D, Grover L, Quinn B, editors. Intimacy \& Sexuality for Cancer Patients and their Partners a Booklet of Tips \& Ideas for your Journey of Recovery. 2005. p.37-80. http://www. newcastle-hospitals.org.uk/downloads/Cancer\%20Services\%20 Slides/Intimacy_and_Sexuality__For_Cancer_Patients_and_ their_Partners.pdf

2. Carter J, Lacchetti C, Andersen BL, Barton DL, Bolte S, Damast $S$, et al. Interventions to address sexual problems in people with cancer: American Society of Clinical Oncology clinical practice guideline adaptation of Cancer Care Ontario guideline. J Clin Oncol 2017;36:492-511. [CrossRef]

3. Çavdar İ. Meme kanserli hastalarda cinsel sorunlar. Meme Sağlığı Derg 2006;2(2):64-6.

4. Brandenburg D. Sex in Context: How the Rest of our Lives Influences Sexual Functioning. (Chapter 2). In: Brandenburg D, Grover L, Quinn B, editors.Intimacy \& Sexuality for Cancer Patients and their Partners a Booklet of Tips \& Ideas for your Journey of Recovery. 2005. p.8-13. http://www.newcastle-hospitals.org.uk/downloads/ Cancer\%20Services\%20Slides/Intimacy_and_Sexuality__For_ Cancer_Patients_and_their_Partners.pdf

5. Quinn B. Sexual Side Effects of Cancer Treatments and the Person Living with Cancer. (Chapter 4). In: Brandenburg D, Grover L, Quinn B, editors.Intimacy \& Sexuality for Cancer Patients and their Partners a Booklet of Tips \& Ideas for your Journey of Recovery. 2005. p.22-36. http://www.newcastle-hospitals.org. uk/downloads/Cancer\%20Services\%20Slides/Intimacy_and_ Sexuality_For_Cancer_Patients_and_their_Partners.pdf

6. Barbera L, Zwaal C, Elterman D, McPherson K, Wolfman W, Katz A, Matthew A. Interventions to address sexual problems in people with cancer. Curr Oncol 2017;24:192-200. [CrossRef]

7. Brandenburg D. The Sexual Response Cycle and Cancer. (Chapter 3). In: Brandenburg D, Grover L, Quinn B, editors.Intimacy \& Sexuality for Cancer Patients and their Partners a Booklet of Tips \& Ideas for your Journey of Recovery. 2005. p.14-21. http://www. newcastle-hospitals.org.uk/downloads/Cancer\%20Services\%20 Slides/Intimacy_and_Sexuality__For_Cancer_Patients_and_ their_Partners.pdf

8. Reis N. Jinekolojik kanser ve tedavisinin kadın cinsel sağlığına etkileri. C. Ü. Hemşirelik Yüksek Okulu Derg 2003;7:35-40. http://eskidergi.cumhuriyet.edu.tr/makale/629.pdf 
9. Herbenick D, Reece M, Hollub A, Satinsky S, Dodge B. Young female breast cancer survivors: their sexual function and interest in sexual enhancement products and services. Cancer Nurs 2008;31:417-25. [CrossRef]

10. Kirby R, Watson A, Newling D. Prostate cancer and sexual functioning. Prostate Cancer Prostatic Dis 1998;1:179-84. [CrossRef]

11. Quinn B. Sexual health in cancer care. Nurs Times 2003;99:32-4.

12. Krebs LU. Sexual and reproductive dysfunction. In: Yarbro $\mathrm{CH}$, Wujic D, Goebel BH, editors. Cancer Nursing, 7th ed. Sudbury, MA: Jones and Bartlett Publishers; 2011. pp.879-911,.

13. Dizon DS, Suzin D, Mcllvenna S. Sexual health as a survivorship issue for female cancer survivors. Oncologist 2014;19:202-10. [CrossRef]

14. Olsson C, Berglund AL, Larsson M, Athlin E. Patient's sexuality-A neglected area of cancer nursing? Eur J Oncol Nurs 2012;16:42631. [CrossRef]

15. McGrath PD. The impact on sexuality after diagnosis and treatment for a hematologic malignancy: findings from Australia. Oncol Nurs Forum 2012;39:595-600. [CrossRef]

16. Steentjes L, Siesling S, Drummond FJ, van Manen JG, Sharp L, Gavin A. Factors associated with current and severe physical sideeffects after prostate cancer treatment: What men report. Eur J Cancer Care (Engl) 2018;27:e12589. [CrossRef]

17. van den Bergh RC, Korfage IJ, Roobol MJ, Bangma CH, de Koning HJ, Steyerberg EW, Essink-Bot ML. Sexual function with localized prostate cancer: active surveillance vs radical therapy. BJU Int 2012;110:1032-9. [CrossRef]

18. Carter J, Lacchetti C, Andersen BL, Barton DL, Bolte S, Damast $S$, et al. Interventions to address sexual problems in people with cancer: American Society of Clinical Oncology clinical practice guideline adaptation of Cancer Care Ontario guideline. J Clin Oncol 2017;36:492-511. [CrossRef]

19. Walker LM, Santos-Iglesias P, Robinson J. Mood, sexuality, and relational intimacy after starting androgen deprivation therapy: implications for couples. Support Care Cancer 2018;26:3835-42. [CrossRef]

20. Talcott JA, Rieker P, Propert KJ, Clark JA, Kantoff PW, Wishnow $\mathrm{KI}$, et al. Patient-reported impotence and incontinence after nervesparing radical prostatectomy. J Natl Cancer Inst 1997;89:111723. [CrossRef]

21. Olsson C, Sandin-Bojö A, Bjuresäter K, Larsson M. Patients treated for hematologic malignancies: affected sexuality and health-related quality of life. Cancer Nurs 2015;38:99-110. [CrossRef]

22. Fokdal L, Høyer M, Meldgaard P, von der Maase H. Long-term bladder, colorectal, and sexual functions after radical radiotherapy for urinary bladder cancer. Radiother Oncol 2004;72:139-45. [CrossRef]

23. Gacci M, Baldi E, Tamburrino L, Detti B, Livi L, De Nunzio C, et al. Quality of life and sexual health in the aging of PCa survivors. Int J Endocrinol 2014;2014:470592. [CrossRef]

24. Özbey İ. Kemoterapi ve erkek infertilitesi. Androloji Bülteni 2011;45:123-27. http://file.lookus.net/androlojibulteni/ Haziran-2011-45.Say\%C4\%B1.pdf

25. Jonker-Pool G, Hoekstra HJ, van Imhoff GW, Sonneveld DJA, Sleijfer DT, van Driel MF, et al. Male sexuality after cancer treatment —needs for information and support: testicular cancer compared to malignant lymphoma. Patient Educ Counsel 2004;52:143-50. [CrossRef]

26. Noyan MA. Mesane kanseri hastasına psikiyatrik yaklaşım ilkeleri ve üroonkologlara öneriler. Psikoonkoloji 2012;11:305-10.
27. Jayne DG, Brown JM, Thorpe H, Walker J, Quirke P, Guillou PJ. Bladder and sexual function following resection for rectal cancer in a randomized clinical trial of laparoscopic versus open technique. Br J Surg 2005;92:1124-32. [CrossRef]

28. Colombo R, Bertini R, Salonia A, Naspro R, Ghezzi M, Mazzoccoli $\mathrm{B}$, et al. Overall clinical outcomes after nerve and seminal sparing radical cystectomy for the treatment of organ confined bladder cancer. J Urol 2004;171:1819-22. [CrossRef]

29. Asoglu O, Matlim T, Karanlik H, Atar M, Muslumanoglu M, Kapran Y, et al. Impact of laparoscopic surgery on bladder and sexual function after total mesorectal excision for rectal cancer. Surg Endosc 2009;23:296-303. [CrossRef]

30. Hendren SK, O’Connor BI, Liu M, Asano T, Cohen Z, Swallow CJ, et al. Prevalence of male and female sexual dysfunction is high following surgery for rectal cancer. Ann Surg 2005:242:212-23. [CrossRef]

31. Tiryaki A, Özkorumak E, Civil Aslan F, Yavuz AA. Remisyonda testis kanseri hastalarında cinsel doyum ve yaşam kalitesi. Anadolu Psikiyatri Derg 2009;10:233-8. https://docplayer.biz. tr/14505666-Remisyonda-testis-kanseri-hastalarinda-cinseldoyum-ve-yasam-kalitesi.html

32. Traa MJ, De Vries J, Roukema JA, Den Oudsten BL. Sexual (dys) function and the quality of sexual life in patients with colorectal cancer: a systematic review. Ann Oncol 2011;23:19-27. [CrossRef]

33. Crook J, Esche B, Futter N. Effect of pelvic radiotherapy for prostate cancer on bowel, bladder, and sexual function: the patient's perspective. Urology 1996;47:387-94. [CrossRef]

34. Havenga K, Maas CP, DeRuiter MC, Welvaart K, Trimbos JB. Avoiding long-term disturbance to bladder and sexual function in pelvic surgery, particularly with rectal cancer. Semin Surg Oncol 2000:18:235-43. [CrossRef]

35. Greaves P, Sarker SJ, Chowdhury K, Johnson R, Matthews J, Matthews R, et al. Fertility and sexual function in long-term survivors of haematological malignancy: using patient-reported outcome measures to assess a neglected area of need in the late effects clinic. Br J Haematol 2014;164:526-35. [CrossRef]

36. Sprangers MAG, Taal BG, Aaronson NK, te Velde A. Quality of life in colorectal cancer. Dis Colon Rectum 1995;38:361-9. [CrossRef]

37. Kocaman Yıldırım N, Kaçmaz N, Özkan M. İleri evre kanser hastalarının karşılanmamış bakım gereksinimleri. Psikiyatri Hemşireliği Derg 2013;4:153-8. [CrossRef]

38. Olsson C, Sandin-Bojö AK, Bjuresäter K, Larsson M. Changes in sexuality, body image and health related quality of life in patients treated for hematologic malignancies: A longitudinal study. Sex Disabil 2016;34:367-88. [CrossRef]

39. Melissant HC, Jansen F, Schutte LER, Lissenberg-Witte BI, Buter J, Leemans CR, et al. The course of sexual interest and enjoyment in head and neck cancer patients treated with primary (chemo) radiotherapy. Oral Oncol 2018;83:120-6. [CrossRef]

40. Tuğut N, Gölbaşı Z. Cinselliğin değerlendirilmesinde PLISSIT modeli'nin kullanımı. Gümüşhane Üniversitesi Sağlık Bilimleri Derg 2013;2(3):524-34. https://dergipark.org.tr/tr/download/ article-file/84260

41. Duldt BW, Pokorny ME. Teaching communication about human sexuality to nurses and other healtcare providers. Nurs Educ 1999;24:27-32. [CrossRef]

42. Pühse G, Wachsmuth JU, Kemper S, Husstedt IW, Evers S, Kliesch $S$. Chronic pain has a negative impact on sexuality in testis cancer survivors. J Andrology 2012;33:886-93. [CrossRef]

43. Can G. Kanserde cinsel sağlık. Androloji Bülteni 2004;19:355-6. http://file.lookus.net/androlojibulteni/Kas\%C4\%B1m-2004-19. Say\%C4\%B1.pdf 